\title{
Uso do jogo como potencializador da aprendizagem: uma perspectiva de docentes da educação básica
}

Helisabety B. Mendes de Melo helisamendes@hotmail.com orcid.org/0000-0002-5994-6621 Instituto Federal de Alagoas (IFAL), Maceió, Alagoas, Brasil

\section{RESUMO}

O presente artigo é um recorte da pesquisa de mestrado desenvolvida no Programa de pósgraduação em Educação em Ciências e Matemática da Universidade Federal de Pernambuco, o trabalho desenvolvido tem como objetivo apresentar a análise sobre a perspectiva de professoras e professores, prioritariamente do Ensino Fundamental, que atuam em escolas da rede pública municipal de Maceió/AL parceiras da Mind Lab na aplicação do Programa Mentelnovadora, no sentido de identificarmos se os mesmos têm clareza ou não de como o uso dos jogos enquanto metodologia de ensino podem potencializar o processo de ensino e aprendizagem e favorecer o desenvolvimento de atitudes propícias para aprendizado do seu componente curricular. A partir de uma metodologia de cunho qualitativo, descritiva e de campo, consultamos professoras e professores de diversas áreas do conhecimento na educação básica e constatou-se um esforço por parte destes(as) para a compreensão da importância do papel do jogo no desenvolvimento humano e cognitivo e no equilíbrio psíquico e emocional, tanto nas crianças, como nos adolescentes e jovens; ainda que percebamos uma tendência de vinculação do ato de brincar em sala de aula com a ideia de passatempo, distração. É aludido nas respostas ao questionário aplicado com os(as) docentes, a partir da Análise de Conteúdo em Bardin (2011), que o jogo por si só não garante a aprendizagem, e que o jogo, assim como a brincadeira, deve ser entendido como uma oportunidade de construção de aprendizagem. Nesse contexto, destacaremos aqui, a perspectiva sobre o uso do jogo na educação em autores como Kishimoto (2003 e 2011), Antunes (1998) e Borin (1998).

PALAVRAS-CHAVE: Jogo. Educação. Metodologia. Ensino. 


\section{INTRODUÇÃO}

Embora existam diversos tipos, formas e modelos de jogos para educação e, ainda, diferentes concepções de como deveriam ser utilizados esses jogos nos diversos níveis e modalidades de ensino, verifica-se, de forma empírica, dois aspectos que são perceptíveis quanto ao uso dos jogos em ambientes de ensino e aprendizagem, são eles: um referente ao entretenimento, para divertir e distrair os jogadores/discentes, e outro referente aos aspectos cognitivos, por meio dos quais os jogos se apresentam com fins pedagógicos, como a possibilidade de crescimento intelectual, além de pessoal e social do jogador/discente.

Entre os vários estudos que discutem o uso do jogo no campo da Educação, alguns consideram que o jogo enquanto metodologia de ensino é um importante potencializador da aprendizagem. Kishimoto (2011), que valoriza o uso do jogo na educação, considera que:

A utilização do jogo potencializa a exploração e a construção do conhecimento, por contar com a motivação interna, típica do lúdico, mas o trabalho pedagógico requer a oferta de estímulos externos e a influência de parceiros, bem como a sistematização de conceitos em outras situações que não jogos (KISHIMOTO, 2011, p.42).

Consequentemente, quando da utilização do jogo como potencializador da aprendizagem, há que se considerar tais aspectos, pois, o seu emprego, tão somente, pelo seu caráter lúdico, ou seja, como um fim em si mesmo, deve ser evitado, afim de que não seja caracterizado como um passatempo. Segundo, Borin (1998):

(...) um determinado jogo é bom se permite várias explorações no sentido de promover o exercício do pensamento crítico daqueles que jogam. Caso contrário, ele se caracteriza como um passatempo e pode ser deixado para os momentos de lazer, quando os aspectos lúdicos e sociais são importantes (BORIN, 1998, p. 18).

Assim, professoras e professores precisam trabalhar com clareza o sentido do jogo, ou seja, com intencionalidade para compreender qual a finalidade maior do trabalho com o jogo e o que é preciso fazer para alcançar os objetivos do ensino com o uso do mesmo. Nesse sentido, Antunes (1998), alerta:

[...] jamais pense em usar jogos pedagógicos sem um rigoroso e cuidadoso planejamento, marcado por etapas nítidas e que efetivamente acompanhem o progresso dos alunos, e jamais avalie sua qualidade de professor pela quantidade de jogos que emprega, e sim pela qualidade dos jogos que se preocupou em pesquisar e selecionar (ANTUNES, 1998, p. 37).

Assim, a pergunta que se pretende responder com a pesquisa é: Qual a percepção de professoras e professores do Ensino Fundamental em relação ao uso dos jogos como metodologia de ensino? Por decorrência, algumas perguntas auxiliares se fazem necessárias: 1) De que forma têm sido utilizados os jogos em sala de aula? 2) Quais os propósitos e critérios que as professoras e professores reconhecem e valorizam quando da utilização dos jogos em suas aulas?

Nesse contexto, podemos afirmar que o objetivo geral da pesquisa é o de investigar a perspectiva de professoras e professores do Ensino Fundamental 
quanto à utilização dos jogos enquanto recurso didático no processo de ensino e aprendizagem. Com isso, serão propostos os seguintes objetivos específicos:

- entender a importância do uso jogo, enquanto atividade lúdica, no Ensino Fundamental;

- reconhecer o papel do(a) professor(a) no desenvolvimento de uma atividade com o uso do jogo;

- compreender o uso do jogo, em sala de aula, associado ao(s) conteúdo(s) e/ou objetivo(s) dentro do processo de ensino-aprendizagem;

- conhecer a experiência pessoal de professoras e professores quanto ao uso do jogo em sala de aula;

- identificar dentre os objetivos socioafetivo, cognitivo e psicomotor do uso do jogo, qual deles é o mais predominante no trabalho docente em sala de aula.

Desse modo, inicialmente tornaremos explícito algumas escolhas metodológicas que subsidiaram a pesquisa. Em seguida, serão detalhados os resultados e discussões obtidos a partir dos dados coletados que incluem reflexões sobre o contributo do uso do jogo na educação e, por fim, serão apresentadas as conclusões.

\section{METODOLOGIA DA INVESTIGAÇÃO}

A metodologia, de cunho qualitativo, adotada para presente investigação se caracteriza sob dois enfoques, conforme GIL (2008): quanto aos objetivos e quanto aos procedimentos técnicos. Para efeito deste trabalho, trata-se de uma pesquisa descritiva, pois descreve as características de determinadas populações ou fenômenos. Quanto aos procedimentos técnicos, será uma pesquisa de campo.

No caso deste estudo, justificam-se tais opções, uma vez que o mesmo consiste em investigar a percepção de professoras e professores, do Ensino Fundamental, em relação ao uso dos jogos em sala de aula. Buscando, o aprofundamento de uma realidade específica, qual seja: professoras e professores do Ensino Fundamental que atuam em escolas da rede pública municipal de Maceió/AL parceiras da Mind Lab na aplicação da metodologia do Programa Mentelnovadora. A metodologia Mind Lab ressalta a importância de resgatar a cultura do lúdico, baseando-se em três pilares interligados: "Jogos de Raciocínio", "Métodos Metacognitivos" e "Professor Mediador". De acordo com o Projeto Pedagógico - Programa Mentelnovadora: "A ênfase da Metodologia está no jogo como instrumento mediador e na ação intencional do educador ao mediar a relação do jovem com a situação de jogo." (Projeto Pedagógico Mind Lab, 2009, p.06).

Para investigar a questão da pesquisa, o estudo de campo foi realizado por meio da observação e aplicação de um questionário. O questionário aplicado apresentava 10 (dez) perguntas, divididas em duas partes: questionário demográfico e uso do jogo em sala de aula. A primeira parte é composta por 8 (oito) questões fechadas que enfocam dados pessoais e profissionais dos(as) participantes da pesquisa e a segunda parte, formadas por 2 (duas) questões 
abertas que exploram a experiência docente quanto ao uso do jogo em sala de aula. Os dados obtidos em cada uma das questões fechadas, serão tabulados para torná-los mais claros e informativos, enquanto que as respostas às questões abertas do questionário serão fundamentadas nos pressupostos da metodologia de Análise de Conteúdo (AC) em Bardin (2011).

Bardin (2011), considera que a análise do conteúdo é um conjunto de instrumentos de cunho metodológico em constante aperfeiçoamento, que se aplicam a discursos (conteúdos e continentes) extremamente diversificados e ressalta a importância do rigor na utilização da análise de conteúdo, a necessidade de superação das incertezas, e compreensão do que é questionado.

Nessa perspectiva, em nosso trabalho, efetuaremos a realização das etapas do método segundo Bardin (2011, p.125), o qual as organiza em três polos cronológicos: 1) a pré-análise, 2) a exploração do material e 3) o tratamento dos resultados e interpretações.

A pré-análise tem por objetivo a organização do material de pesquisa e, é compreendida por Bardin (2011) como sendo a fase de leitura "flutuante" e, ainda, da escolha dos documentos. Segundo Bardin (2011, p.126), esta fase "consiste em estabelecer contato com os documentos a analisar e em conhecer o texto deixando-se invadir por impressões e orientações." ou seja, inicia-se as primeiras interações com os documentos que serão submetidos à análise e selecionam-se, dentre os documentos disponíveis, aqueles suscetíveis de fornecerem informações sobre o problema de pesquisa.

A segunda etapa, ou fase de exploração do material são definidas as categorias de análise, as operações de codificação, decomposição e enumeração do corpus da pesquisa. De acordo com Bardin, "Esta fase, longa e fastidiosa, consiste essencialmente em operações de codificação, decomposição ou enumeração, em função de regras previamente formuladas" (2011, p. 131).

Na última fase de tratamento dos dados, segundo Bardin (2011, p. 131), "Os resultados brutos são tratados de maneira a serem significativos (falantes) e válidos." É, portanto, uma fase de interpretação/análise dos dados obtidos.

\section{RESULTADOS E DISCUSSÃO}

Apresentamos, a seguir, a análise das respostas à primeira parte do questionário que são os dados demográficos dos 55 participantes da pesquisa: professoras e professores capacitados(as) a atuar na Educação Básica e que, prioritariamente, tenham experiência no Ensino Fundamental em escolas da rede pública municipal de Maceió/AL parceiras da Mind Lab na aplicação da Metodologia do Programa Mentelnovadora. O objetivo é caracterizar os docentes por variável representativa do questionário, como gênero, faixa etária, nível de escolaridade, área de atuação de ensino, tempo de experiência lecionando e frequência em cursos de formação continuada com a temática do jogo na educação, etc. Em seguida, a análise dessas respostas permitirá identificar o perfil dos docentes participantes da pesquisa.

Como pode ser visto nas tabelas abaixo, os itens que mais se destacaram foram referentes à predominância do gênero feminino e a faixa etária dos(as) 
docentes variando entre 40 a 49 anos. Entretanto, quanto à predominância do gênero feminino, deve-se considerar que atualmente a feminização da profissão docente é uma condição historicamente reconhecida.

Tabela 1 - Gênero dos(as) docentes participantes da pesquisa

\begin{tabular}{cc} 
Gênero & Percentual \\
\hline Feminino & $69,1 \%$ \\
\hline Masculino & $30,9 \%$ \\
\hline
\end{tabular}

Fonte: Autoria própria (2017/2018).

Tabela 2 - Faixa etária dos(as) docentes participantes da pesquisa

\begin{tabular}{cc} 
Idade & Percentual \\
Até 24 anos & $0 \%$ \\
\hline Entre 25 e 29 anos & $3,6 \%$ \\
\hline Entre 30 e 39 anos & $21,8 \%$ \\
\hline Entre 40 e 49 anos & $45,5 \%$ \\
\hline Entre 50 e 54 anos & $16,4 \%$ \\
\hline Acima de 55 anos & $12,7 \%$ \\
\hline
\end{tabular}

Fonte: Autoria própria (2017/2018).

Na Tabela 3, as respostas referentes ao tempo de docência indicam que a maior parte dos(as) docentes participantes da pesquisa possuem mais de 20 anos de tempo de trabalho como professor(a).

Tabela 3 - Tempo de Trabalho dos(as) docentes participantes da pesquisa

\begin{tabular}{cc} 
Tempo de trabalho & Percentual \\
Meu primeiro ano & $0 \%$ \\
\hline Entre 1 e 2 anos & $0 \%$ \\
\hline Entre 3 e 5 anos & $3,6 \%$ \\
\hline Entre 6 e 10 anos & $25,5 \%$ \\
\hline Entre 11 e 15 anos & $25,5 \%$ \\
\hline Entre 16 e 20 anos & $18,2 \%$ \\
\hline Acima de 20 anos & $27,3 \%$ \\
\hline
\end{tabular}

Fonte: Autoria própria (2017/2018).

Outro aspecto analisado, relacionado à jornada de trabalho desses(as) docentes, observa-se abaixo na Tabela 4, referente à questão: "Possui jornada dupla ou tripla de trabalho como professor(a)?" que, a resposta "Sim", obteve índice pouco inferior a predominante "Não". Significa dizer que, pouco mais de $50 \%$ dos(as) docentes respondentes do questionário, não possui jornada dupla ou tripla de trabalho, trabalhando apenas em uma escola. 
Tabela 4 - Jornada de trabalho dos(as) docentes participantes da pesquisa

Jornada dupla ou tripla de trabalho Sim

Não

\section{Percentual}

$41,8 \%$

$58,2 \%$

Fonte: Autoria própria (2017/2018).

De acordo com a Tabela 5 abaixo, aproximadamente $70 \%$ dos(as) docentes respondentes do questionário, participaram nos últimos dois anos de alguma atividade de formação continuada (atualização, treinamento, capacitação etc.) com a temática sobre o uso dos jogos na educação. De todo modo, vale destacar que, prioritariamente, as escolas selecionadas para aplicação do questionário, foram escolas parceiras na aplicação do Programa Mentelnovadora, que é uma proposta curricular que propõe uma disciplina chamada Jogos e prevê formações continuadas para os(as) professores(as) dessas escolas para aplicação dos jogos que são desenvolvidos pelo programa.

Tabela 5 - Formação Continuada dos(as) docentes respondentes e participantes da pesquisa

\begin{tabular}{cc} 
Formação Continuada & Percentual \\
\hline Sim & $69,1 \%$ \\
\hline Não & $30,9 \%$ \\
\hline
\end{tabular}

Fonte: Autoria própria (2017/2018).

Quanto a escolaridade dos(as) docentes respondentes e participantes da pesquisa, as respostam revelam que todos(as) os(as) docentes possuem nível superior. Conforme apontado na tabela abaixo:

Tabela 6 - Escolaridade dos(as) docentes participantes da pesquisa

\begin{tabular}{cc} 
Escolaridade & Percentual \\
\hline Ensino Médio - Magistério (Antigo 2o grau) & $0 \%$ \\
\hline Ensino Superior - Escola Normal Superior & $1,8 \%$ \\
\hline Ensino Superior - Pedagogia & $43,6 \%$ \\
\hline Ensino Superior - Outra Licenciatura & $54,5 \%$ \\
\hline
\end{tabular}

Fonte: Autoria própria (2017/2018).

Em relação a curso de pós-graduação, conforme a Tabela 7 a seguir, houve um número reduzido de docentes com curso de pós-graduação stricto sensu (Mestrado ou Doutorado), a maioria dos(as) docentes com pós-graduação tem, somente, especialização. O(a) docente de mais alta titulação possui mestrado. 
Tabela 7 - Curso de Pós-Graduação dos(as) docentes participantes da pesquisa

\begin{tabular}{cc} 
Curso de Pós-Graduação & Percentual \\
\hline Especialização & $70,9 \%$ \\
\hline Mestrado & $7,3 \%$ \\
\hline Doutorado & $0 \%$ \\
\hline Não fiz ou incompleto & $21,8 \%$ \\
\hline
\end{tabular}

Fonte: Autoria própria (2017/2018).

Conforme Tabela 8 abaixo, a área de conhecimento de maior concentração dos(as) docentes respondentes e participantes da pesquisa, representando quase $50 \%$ do total de participantes, é nas Séries Iniciais do Ensino Fundamental com formação em Pedagogia.

Tabela 8 - Área do conhecimento dos(as) docentes respondentes e participantes da pesquisa

\begin{tabular}{cc} 
Área do conhecimento & Percentual \\
\hline E. F. Séries Iniciais & $45,4 \%$ \\
\hline Português & $10,9 \%$ \\
\hline Matemática & $16,4 \%$ \\
\hline História & $7,3 \%$ \\
\hline Geografia & $5,5 \%$ \\
\hline Ensino Religioso & $0 \%$ \\
\hline Artes & $0 \%$ \\
\hline Ciências & $10,9 \%$ \\
\hline Língua Estrangeira & $0 \%$ \\
\hline Educação Física & $3,6 \%$ \\
\hline
\end{tabular}

Fonte: Autoria própria (2017/2018).

Como pode ser visto na tabela acima, na constituição dos docentes participantes da pesquisa, é maior a participação de professores das Séries Iniciais do Ensino Fundamental. Entretanto, deve-se considerar que o número de matrículas nas séries iniciais do Ensino Fundamental é maior do que os de 6으 a 9으 ano, segundo os dados informados na 1a etapa do Censo Escolar 2017 do município de Maceió.

Finalizada a análise das respostas da primeira parte do questionário, seguiremos para segunda parte do questionário. Para se proceder à análise das respostas à questão aberta 9 "Como educador(a), qual a sua opinião sobre a importância do uso do jogo na Educação Básica?" e questão aberta 10 "No seu ponto de vista, o uso do jogo em sala de aula, deve estar devidamente associado ao(s) conteúdo(s) e/ou objetivo(s) dentro do processo de ensino aprendizagem? Justifique:", formulou-se, intuitivamente, duas hipóteses provisórias que supostamente pudessem responder a questão da pesquisa: Qual concepção de professoras e professores capacitados(as) a atuar na Educação Básica e que, prioritariamente, estejam vinculados(as) às escolas da rede pública municipal de 
Maceió/AL parceiras da Mind Lab na aplicação da Metodologia do Programa Mentelnovadora, quanto à utilização dos jogos em sala de aula?, que são as seguintes:

a) na concepção desses(as) docentes o uso dos jogos como metodologia de ensino é um potencializador da aprendizagem, pois contempla, ao mesmo tempo, o seu aspecto lúdico e educativo;

b) na concepção desses(as) docentes o uso dos jogos como metodologia de ensino é um passatempo, em virtude de existir uma tendência de vinculação do ato de brincar em sala de aula com a ideia de passatempo;

Por outro lado, a partir da leitura das diferentes fases da análise de conteúdo e descobertas durante os estudos em relação aquilo que está além do método, mas que faz parte do contexto e circunstâncias da pesquisa, observou-se a necessidade de recorremos a um nível maior de teorização que nos permitisse remeter as respostas obtidas a um sentido suplementar as duas hipóteses. Com efeito, formulou-se a terceira hipótese:

c) na concepção desses(as) docentes o uso dos jogos como metodologia de ensino é um instrumento do(a) professor(a), uma vez que o seu aspecto lúdico é colocada em segundo plano em detrimento do educativo.

Definidas as hipóteses, ainda que não sejam obrigatórias para se proceder à análise, pois para Bardin (2011, p. 128) “Algumas análises efetuam-se 'às cegas' e sem ideias preconcebidas." Mas, nesse caso, como optamos por um trabalho orientado por hipóteses, em função dessas, considerou-se uma prévia formulação de categorias (categorização a priori). De acordo com Bardin (2011), as categorias podem ser criadas a priori ou a posteriori, isto é, a partir apenas da teoria ou após a coleta de dados e, quando se parte da verificação de hipóteses previamente definidas as categorias podem ser estabelecidas de antemão.

Ainda de acordo com Bardin (2011, p. 148 e 149) "A categorização tem como primeiro objetivo (da mesma maneira que a análise documental) fornecer, por condensação, uma representação simplificada dos dados brutos." Dessa forma, designamos três categorias apriorísticas:

1. o jogo é um potencializador da aprendizagem;

2. o jogo é um passatempo;

3. o jogo é um instrumento do(a) professor(a).

Desse modo, para análise temática, passa-se a construção da definição de cada categoria e, que neste caso, parte do arcabouço teórico da pesquisa e, especialmente, de Kishimoto (2003 e 2011), pela sua competência, sensibilidade e experiência em pesquisas sobre o lúdico na educação. A questão primeira encontrada em seus escritos é que o jogo é um fato social e como tal assume diferentes concepções e sentidos conforme o modo de vida e valores construídos em cada sociedade, daí o fato do jogo ser concebido de formas diferentes a depender do contexto histórico-social. "Enfim, cada contexto social constrói uma imagem de jogo conforme seus valores e modo de vida, que se expressa por meio da linguagem". (KISHIMOTO, 2011, p.19).

Porém, por conseguinte, é necessário que se compreenda a dinâmica que o jogo assume em contextos escolares e que se perceba a importância e os impasses 
a serem superados em relação às funcionalidades do jogo na educação. Nesse momento, a pretensão é tirar algumas lições a partir das considerações sobre as relações entre jogo e educação em Kishimoto $(2002,2003$ e 2011) e o que as suas pesquisas demonstram, a fim de traçar as regras de funcionalidade do jogo na educação. No tocante ao uso do jogo em sala de aula, Kishimoto (2003) faz algumas reflexões sobre as muitas dúvidas que ainda persistem entre educadores e afirma que:

\footnotetext{
Se brinquedos são sempre suportes de brincadeiras, sua utilização deveria criar momentos lúdicos de livre exploração, nos quais prevalece a incerteza do ato e não se buscam resultados. Porém, se os mesmos objetos servem como auxiliar da ação docente, buscam-se resultados em relação a aprendizagem de conceitos e noções, ou mesmo, ao desenvolvimento de algumas habilidades. Nesse caso, o objeto conhecido como brinquedo não realiza sua função lúdica, deixa de ser brinquedo para tornar-se material pedagógico. Um mesmo objeto pode adquirir dois sentidos conforme o contexto em que se utiliza: brinquedo ou material pedagógico (Kishimoto, 2003, p.14)
}

Dessa maneira, Kishimoto (2003) identifica o brinquedo e material pedagógico pelo aspecto da validade e funcionalidade desses objetos. Caracterizando, por vezes, os mesmos objetos, ora como brinquedo, em função da sua ludicidade e ora como material pedagógico, em razão de fazer uso deste, com a finalidade de resultados em relação a aprendizagem. Assim, podemos perceber que os mesmos objetos, servem para o brincar livre, com o fim em si mesmo e, ao mesmo tempo, podem ser utilizados por professoras e professores com vistas a atingir determinados objetivos educativos, deixando de ser brinquedo para tornar-se material pedagógico.

Diríamos então, que a afirmação de Kishimoto (2003) nos permite inferir que o jogo pelo jogo em sala de aula torna-se um brinquedo e que esse mesmo jogo pode constituir-se em material pedagógico, na verdade, em mais um instrumento do ensino se utilizado para construção de aprendizagem de conceitos e habilidades, por exemplo. Assim, a apropriação dessas ideias em Kishimoto (2003) leva-nos a dois sentidos com relação ao uso dos jogos em sala de aula: os jogos como brinquedo, destinado ao brincar de forma livre e que seja assegurada a sua função lúdica e os jogos como material pedagógico, especificamente, voltado para o ensino sem comportar os seus aspectos lúdicos.

Segundo Kishimoto o termo brinquedo é imprescindível para entendermos melhor sobre o jogo. "[...] Diferindo do jogo, o brinquedo supõe uma relação íntima com a criança e uma indeterminação quanto ao uso, ou seja, a ausência de um sistema de regras que organizam sua utilização." (2011, p. 20). Por outro lado, o jogo educativo, é para autora, um jogo em que a função lúdica não se sobressai ao aspecto educativo e vice-versa. No seu entender, "O equilíbrio entre as duas funções é o objetivo do jogo educativo” (KISHIMOTO, 2003, p. 19).

Do ponto de vista da autora, o significado atribuído ao jogo incorporado a escola como sendo o "jogo educativo" alicia dizermos que, diferentemente do brinquedo e do material pedagógico, possui harmonia entre a função lúdica e a educativa. Kishimoto (2003) diz que o objetivo do jogo educativo é o equilíbrio entre a função lúdica e a educativa, afirmando que a predominância da função lúdica em detrimento da função educativa anula o ensino e, o contrário, quando a 
função educativa sobressai, elimina-se o prazer no jogo, restando somente o ensino (KISHIMOTO, 2003, p.19). A autora ainda exemplifica que:

\begin{abstract}
Se um professor escolhe um jogo de memória com estampas de frutas destinado a auxiliar na discriminação das mesmas, mas as crianças utilizam as cartas do jogo para fazer pequenas construções, a função lúdica predomina e absorve o aspecto educativo definido pelo professor: discriminar frutas. Da mesma forma, certos jogos perdem rápido a sua dimensão lúdica quando empregados inadequadamente. $O$ uso de quebra-cabeça e jogos de encaixes como modalidade de avaliação constrange e elimina a ação lúdica. Se perde a sua função de propiciar prazer em proveito da aprendizagem, o brinquedo se torna instrumento de trabalho, ferramenta do educador. O "brinquedo" já não é brinquedo, é material pedagógico ou didático. (KISHIMOTO, 2003, p.19).
\end{abstract}

Com isso, a autora admite a provisoriedade da função do jogo no contexto escolar, nos permitindo anunciar a multifuncionalidade do jogo na educação. Se o jogo passa a ser brinquedo quando "a função lúdica predomina e absorve o aspecto educativo definido pelo professor" e este tornar-se material pedagógico ou didático quando ocorre o inverso, pensamos que um caminho interessante a ser percorrido é o de expor as funções do jogo nesse movimento, assumindo as contradições pedagógicas que o jogo com a função educativa definida pelo(a) professor(a) pode adquirir em sala de aula, tentando apreender delas as situações de aprendizagem experimentada pelos(as) educandos(as) com o jogo. Do que se conclui, como salienta Kishimoto (2003), que:

\footnotetext{
Qualquer jogo empregado pela escola aparece sempre como um recurso para a realização das finalidades educativas e, ao mesmo tempo, um elemento indispensável ao desenvolvimento infantil. Se a criança age livremente no jogo de faz de conta dentro de uma sala de educação infantil, expressando relações que observa no seu cotidiano, a função pedagógica será garantida pela organização do espaço, pela disponibilidade de materiais e muitas vezes pela própria parceria do professor nas brincadeiras. (KISHIMOTO, 2003, p.22)
}

Do registro e da análise dessas afirmações, descritas acima, um dos principais impasse a serem superados em relação ao uso do jogo na educação nos parece ser o de revisão e reafirmação da função pedagógica intrínseca no jogo empregado em sala de aula. Pois, ainda que o jogo apresente-se com uma função educativa definida pelo(a) professor(a) e no momento de socialização junto aos educandos(as) se revele diversa da sua intencionalidade: brinquedo ou material pedagógico, em todas elas, há a marca de um projeto educativo. Kishimoto (2011), esclarece que:

Quando as situações lúdicas são intencionalmente criadas pelo adulto com vistas a estimular certos tipos de aprendizagem, surge a dimensão educativa. Desde que mantidas as condições para a expressão do jogo, ou seja, a ação intencional da criança para brincar, o educador está potencializando as situações de aprendizagem. (KISHIMOTO, 2011, p. 41).

Desse modo, independentemente da natureza do jogo e da intenção admitida pelo(a) professor(a) na aplicação do jogo em sala de aula, a função desempenhada pelo jogo é determinada pelo tipo de interação estabelecida entre o(a) professor(a), o jogo e seus(suas) educandos(as). 
Sendo assim, a criação e classificação das categorias que foram demonstradas nesta seção emergem a partir dessas ponderações sobre o que se entende por brinquedo, material pedagógico e jogo educativo em Kishimoto (2003). Imprimindo um significado a partir do qual nos leva a compreender que a concepção de professoras e professores quanto a utilização do jogo como metodologia de ensino pode apresentar-se associado ao uso do jogo como brinquedo; como material pedagógico ou didático ou como jogo educativo.

Assim, tomando-se por base à teoria aqui apresentada, nas respostas à questão 9 e 10, pretende-se identificar proposições portadoras de significações para classificação em função de três temas:

TEMA 1: O jogo é um potencializador da aprendizagem (jogo educativo);

TEMA 2: O jogo é um passatempo (brinquedo);

TEMA 3: O jogo é um instrumento do(a) professor(a) (jogo como material pedagógico ou didático).

Trata-se, então, de extrair significações contidas nas respostas à questão 9 e 10 que teoricamente remetem para o uso do jogo educativo (O jogo é um potencializador da aprendizagem) ou uso do jogo como brinquedo ( $O$ jogo é um passatempo) ou, ainda, o uso do jogo como material pedagógico ou didático ( $\mathrm{O}$ jogo é um instrumento do(a) professor(a)). Tendo em vista que, segundo Bardin (2011):

O tema, enquanto unidade de registro, corresponde a uma regra de recorte (do sentido e não da forma) que não é fornecida, visto que o recorte depende do nível de análise e não de manifestações formais reguladas. Não é possível existir uma definição de análise temática, da mesma maneira que existe uma definição linguística (BARDIN, 2011, p.135)

No plano prático, as respostas à questão 9 e 10, ou seja, um total de 110 (cento e dez) respostas, serão submetidas a um tratamento prioritariamente qualitativo, com análise comparativa com o quadro e a síntese sobre o uso do jogo em sala de aula. Assim se tem:

Quadro 1 - O uso do jogo em sala de aula por Categorias Temáticas

\begin{tabular}{|c|c|c|}
\hline Categorias Temáticas & Descrição & Critérios relativos a teoria \\
\hline $\begin{array}{l}\text { I. O jogo como } \\
\text { metodologia de ensino } \\
\text { potencializa a } \\
\text { aprendizagem; }\end{array}$ & $\begin{array}{l}\text { As respostas à questão } \\
9 \text { e 10, prestam-se } \\
\text { mais à concepção do } \\
\text { jogo educativo: } \\
\text { contempla, ao mesmo } \\
\text { tempo, o aspecto } \\
\text { lúdico e educativo. }\end{array}$ & $\begin{array}{c}\text { “O equilíbrio entre as duas } \\
\text { funções é o objetivo do jogo } \\
\text { educativo." (KISHIMOTO, 2003, } \\
\text { p.19) }\end{array}$ \\
\hline $\begin{array}{c}\text { II. O jogo como } \\
\text { metodologia de ensino é } \\
\text { um passatempo }\end{array}$ & $\begin{array}{l}\text { As respostas à questão } \\
9 \text { e 10, prestam-se } \\
\text { mais à concepção do } \\
\text { jogo como brinquedo, } \\
\text { em virtude de uma } \\
\text { tendência cultural de } \\
\text { vinculação do ato de }\end{array}$ & $\begin{array}{c}\text { "Se brinquedos são sempre } \\
\text { suportes de brincadeiras, sua } \\
\text { utilização deveria criar } \\
\text { momentos lúdicos de livre } \\
\text { exploração, nos quais }\end{array}$ \\
\hline
\end{tabular}




\begin{tabular}{|c|c|c|}
\hline \multirow[t]{2}{*}{ Categorias Temáticas } & Descrição & Critérios relativos a teoria \\
\hline & $\begin{array}{c}\text { brincar em sala de aula } \\
\text { com a ideia de } \\
\text { passatempo. }\end{array}$ & $\begin{array}{l}\text { prevalece a incerteza do ato e } \\
\text { não se buscam resultados. }\end{array}$ \\
\hline $\begin{array}{l}\text { III. O jogo como } \\
\text { metodologia de ensino é } \\
\text { um instrumento do(a) } \\
\text { professor(a). }\end{array}$ & $\begin{array}{l}\text { As respostas à questão } \\
9 \text { e 10, prestam-se } \\
\text { mais à concepção do } \\
\text { jogo como material } \\
\text { pedagógico ou didático } \\
\text { é quando o seu } \\
\text { aspecto lúdico é } \\
\text { colocada em segundo } \\
\text { plano em detrimento } \\
\text { do educativo. }\end{array}$ & $\begin{array}{l}\text { servem como auxiliar da ação } \\
\text { docente, buscam-se resultados } \\
\text { em relação a aprendizagem de } \\
\text { conceitos e noções, ou mesmo, } \\
\text { ao desenvolvimento de } \\
\text { algumas habilidades. Nesse } \\
\text { caso, o objeto conhecido como } \\
\text { brinquedo não realiza sua } \\
\text { função lúdica, deixa de ser } \\
\text { brinquedo para tornar-se } \\
\text { material pedagógico. Um } \\
\text { mesmo objeto pode adquirir } \\
\text { dois sentidos conforme o } \\
\text { contexto em que se utiliza: } \\
\text { brinquedo ou material } \\
\text { pedagógico." (KISHIMOTO, } \\
\text { 2003, p.14). } \\
\text { "Se perde sua função de } \\
\text { propiciar prazer em proveito } \\
\text { da aprendizagem, o brinquedo } \\
\text { se torna instrumento de } \\
\text { trabalho, ferramenta do } \\
\text { peducador. O brinquedo já não } \\
\text { (KISHIMOTo, 2003, p. 19). }\end{array}$ \\
\hline
\end{tabular}

Fonte: Autoria própria (2017/2018).

\section{CATEGORIA “O JOGO É UM POTENCIALIZADOR DA APRENDIZAGEM"}

É comum que pais, educandos(as) e até alguns educadores pensem que brincar é somente diversão. Mas não é só isso. A primordial exigência do jogo com a função de potencializar a aprendizagem em sala de aula é a de que a proporção entre o lúdico e o educativo se mantenham em harmonia ao longo da experiência com o jogo, ou seja, a função de brincar e potencializar a aprendizagem são priorizadas simultaneamente. 
Tabela 9 - "O jogo é um potencializador da aprendizagem"

\begin{tabular}{cc} 
Questão & Frequência (n=55) \\
\hline $\begin{array}{c}\text { QUESTÃO 9. Como educador(a), qual a sua opinião sobre a } \\
\text { importância do uso do jogo na Educação Básica? }\end{array}$ & 27 \\
\hline $\begin{array}{c}\text { QUESTÃo 10. No seu ponto de vista, o uso do jogo em sala de } \\
\text { aula, deve estar devidamente associado ao(s) conteúdo(s) e/ou } \\
\text { objetivo(s) dentro do processo de ensino aprendizagem? } \\
\text { Justifique: }\end{array}$ & 38 \\
\hline Fonte: Autoria própria (2017/2018)
\end{tabular}

Fonte: Autoria própria (2017/2018).

Exemplos de algumas das respostas à questão 9:

1. "O jogo na educação possibilita mesclar conhecimento e diversão.";

2. "Além de ser uma ótima oportunidade para os estudantes aprenderem de forma lúdica, auxilia no ensino $\mathrm{x}$ aprendizagem dos mesmos, facilitando a compreensão dos cálculos e desenvolvimento do raciocínio lógico.";

3. "O uso do jogo em sala de aula proporciona ao indivíduo o contato com diversas linguagens, não só leitura e escrita. Desenvolvendo disciplina, respeito às regras e habilidades psicomotoras e aprendizagem do conteúdo.".

Exemplos de algumas das respostas à questão 10:

1. "Toda atividade pedagógica tem que ter objetivos bem estabelecidos e com o jogo não pode ser diferente. Podemos fazer uso do jogo associando-o aos conteúdos das disciplinas lecionadas";

2. "Sim. Pois se torna uma forma de ficar o conteúdo de forma dinâmica e consegue o interesse maior.";

3. "Sim! Uma metodologia correta tende a melhorar os resultados em avaliações porque melhora as habilidades de pensamento.";

4. "Sim. Jogo sem conteúdo é formalismo".

\section{CATEGORIA “O JOGO É UM PASSATEMPO”}

É o emprego do jogo como expressão de criatividade, sem previsibilidade dos acontecimentos e/ou busca por resultados em sala de aula. Caracterizar-se pelo uso do jogo com a tendência de vinculação do ato de brincar com a ideia de passatempo, distração, de folga das atividades escolares obrigatórias. Ainda que, o(a) professor(a) desconsidere ou não, que as situações de ludicidade, livre exploração, descobertas, manifestações espontâneas, são de extrema importância para o processo educativo. 
Tabela 10 - "O jogo é um passatempo"

Questão

Frequência ( $n=55)$

QUESTÃO 9. Como educador(a), qual a sua opinião sobre a importância do uso do jogo na Educação Básica?

05

QUESTÃO 10. No seu ponto de vista, o uso do jogo em sala de aula, deve estar devidamente associado ao(s) conteúdo(s) e/ou objetivo(s) dentro do processo de ensino aprendizagem? Justifique:

Fonte: Autoria própria (2017/2018).

Exemplos de algumas das respostas à questão 9:

1. "O jogo ajuda o professor no trabalho, principalmente, com crianças." A afirmação, refere-se ao jogo como sendo mais apropriado para crianças, pois esta requer situações de ludicidade;

2. "Maravilhoso os jogos lúdicos. Muito importante para divertir.";

3. "A importância do uso dos jogos nas aulas de matemática dar-se-à em função do olhar que os alunos tem dado aos jogos, uma vez que os jogos fazem parte do seu dia-a-dia, o espírito competitivo e em alguns casos colaborativos e eles sentem emoção ao brincar. De fato os jogos atraem a atenção deles.".

Exemplos de algumas das respostas à questão 10:

1. "Não necessariamente. $\mathrm{O}$ jogo deve ser utilizado como forma de aprender brincando.";

2. "Não, o jogo em sala necessariamente não precisa está relacionado ao conteúdo. Ele pode ser usado com diversos objetivos inclusive só por diversão.";

3. "Se ele tiver o objetivo de trabalhar algum tema sim, mas o jogo pode ser utilizado no momento lúdico, de lazer."

\section{CATEGORIA “O JOGO É UM INSTRUMENTO DO(A) PROFESSOR(A)”}

O jogo passa a ser utilizado pelo(a) professor(a) como um instrumento para um determinado fim ou objetivo, deixando de ter, apenas, um fim em si mesmo. Tornando-se um meio para o processo de ensino e aprendizagem. Constitui-se numa atividade intencional que visa a interiorização de certos tipos de aprendizagem e o brincar é colocado em segundo plano, de modo que é preciso criar um espaço, delimitar um tempo e impor critérios para o jogo. O jogo como um instrumento do(a) professor(a) pode até envolver prazer, mas é uma tarefa que prioriza a objetividade e requer responsabilidade, deixando de ser puramente uma atividade recreativa. $O$ jogo deixa de ser uma expressão de liberdade e passa a ser obrigatório, comprometendo aprendizagem e professor(a). Por isso, o jogo como instrumento do(a) professor(a) está associado a uma avaliação do trabalho $\operatorname{dos}($ as) educandos(as). 
Tabela 11 - "O jogo é um instrumento do(a) professor(a)"

\section{Questão}

Frequência ( $n=55)$

QUESTÃO 9. Como educador(a), qual a sua opinião sobre a importância do uso do jogo na Educação Básica?

QUESTÃO 10. No seu ponto de vista, o uso do jogo em sala de aula, deve estar devidamente associado ao(s) conteúdo(s) e/ou objetivo(s) dentro do processo de ensino aprendizagem? Justifique:

Fonte: Autoria própria (2017/2018).

Exemplos de algumas das respostas à questão 9:

1. "Importante para fixar conteúdos.";

2. "Trabalhar conteúdos educativos.";

3. "Desenvolvimento cognitivo do aluno";

4. "Contribui para melhor assimilação dos conteúdos.";

5. "Trabalhar com o raciocínio.";

6. "Uma boa ferramenta para o aprendizado do aluno."

Exemplos de algumas das respostas à questão 10:

1. "Na maioria das vezes sim, pois deve priorizar o aprendizado dos alunos.";

2. "Não necessariamente a conteúdos curriculares, mas sempre deve ter um objetivo claro e definido.";

3. "Depende do seguimento, se for Ed. Infantil não existe problema do jogo ser apenas para socialização. Contudo, se tratando do Ensino Fundamental o jogo precisa sim está associado à conteúdos e objetivos de aprendizagem.".

\section{INFERÊNCIA ÀS RESPOSTAS DAS QUESTÕES NOVE E DEZ}

Com os resultados das questões nove e dez, objetivou-se achar indícios comuns entre as informações contidas nas respostas e as definições de cada categoria de análise, que de alguma forma nos permitisse dizer que o uso do jogo caracteriza-se como potencializador da aprendizagem ou como passatempo ou como instrumento do(a) professor(a).

Questão 9 (nove):

1. "As aulas ficam mais dinamizadas e os alunos se interessam mais."

2. "Não tenho experiência sobre."

3. "Importante."

4. "Fundamental."

5. "Tenho certeza da grande importância do uso do jogo em qualquer faixa etária."

\section{Questão 10 (dez):}

1. "Sim, pra ficar no objetivo." 
2. "Não necessariamente."

3. "Dentro do processo de ensino aprendizagem."

4. "Sim. Relacionar."

Na tabela abaixo, dos(as) 55 professores(as) respondentes da questão nove, 50 tiveram suas respostas válidas para análise e da questão dez, 51 respostas foram validadas. Vejamos as respostas, a seguir, que não tiveram condições de análise pela imprecisão ao que foi solicitado nas referidas questões:

Tabela 12 - Análises das respostas às questões nove e dez

\begin{tabular}{ccc} 
Questão & $\begin{array}{c}\text { Respostas Válidas } \\
\text { Frequência (n=55) }\end{array}$ & $\begin{array}{c}\text { Respostas } \\
\text { Imprecisas } \\
\text { Frequência } \\
\text { (n=55) }\end{array}$ \\
\hline $\begin{array}{c}\text { QUESTÃo 9. Como educador(a), qual a sua opinião } \\
\text { sobre a importância do uso do jogo na Educação } \\
\text { Básica? }\end{array}$ & 50 & 05 \\
\hline $\begin{array}{c}\text { QUESTÃo 10. No seu ponto de vista, o uso do jogo } \\
\text { em sala de aula, deve estar devidamente associado } \\
\text { ao(s) conteúdo(s) e/ou objetivo(s) dentro do } \\
\text { processo de ensino aprendizagem? Justifique: }\end{array}$ & 51 & 04 \\
\hline
\end{tabular}

Fonte: Autoria própria (2017/2018).

E com isso, verificou-se que 27 (54\%) das 50 respostas à questão nove, apontam para o uso do jogo como potencializador da aprendizagem. Enquanto que na questão dez, dentre as 51 respostas válidas para análise, para 38 (69,09\%) desses professores(as) o uso do jogo também é visto como um potencializador da aprendizagem, resultando em um total de 65 respostas (64,35\%) que, em sua maioria, reconhecem a importância educativa do jogo, valorizando assim, o jogo como um potencializador da aprendizagem.

As respostas às questões nove e dez, mostraram ainda, que a segunda categoria com mais respostas enquadradas foi a categoria "Instrumento do(a) professor(a)", totalizando $25(24,75 \%)$ de 101 respostas válidas. Com relação a categoria "Passatempo", na questão nove, houve 4 ( $8 \%$ ) enquanto que na questão dez, $7(13,72 \%)$. Ao mesmo tempo, algumas respostas não demonstraram clareza e/ou objetividade ao que foi perguntado.

\section{CONSIDERAÇÕES FINAIS}

Além de situar a importância educativa do jogo, os resultados relativos ao que foi questionado nas duas questões abertas permitiram conhecer um pouco mais das expectativas desses(as) professores(as) sobre os aprendizados que os jogos propiciam aos seus(suas) alunos(as). Nas respostas, destacou-se ainda a preocupação com o planejamento, com o objetivo e o conteúdo a ser trabalhado com o uso do jogo e, ainda, com o interesse do(a) aluno(a) pelo jogo, detalhes estes que fazem parte do jogo educativo. Teixeira $(2010$, p. 33) afirma que: 
comportamento infantil, espontâneo, que pudesse significar algum valor em si. (TEIXEIRA, 2010, p. 33)

No entanto, o jogo com a função de brincar em sala de aula, apesar do seu caráter "não intencional" do ponto de vista pedagógico, essa prática acaba fazendo sentido, principalmente, para as crianças. O problema é que o jogo com a função de brincar em sala de aula aparece de forma inadequada quando o professor não planeja esses momentos para promover a junção entre o brincar e a aprendizagem com ensino. Para Ide, "O jogo não pode ser visto, apenas, como divertimento ou brincadeira para desgastar energia, pois ele favorece o desenvolvimento físico, cognitivo, afetivo, social e moral." (IDE, 2011, p. 106-107).

Já o jogo como instrumento do(a) professor(a) em sala de aula, ao inverso disso, se constitui numa atividade que visa, exclusivamente, a interiorização de certos tipos de aprendizagem, privilegiando o desenvolvimento cognitivo do(a) aluno(a). Dessa forma, o jogo passa a ser utilizado pelo(a) professor(a) como um instrumento para um determinado fim ou objetivo, deixando de ter, apenas, um fim em si mesmo, tornando-se um meio para o processo de ensino e aprendizagem. E, assim sendo, deve estar devidamente associado ao(s) conteúdo(s) e/ou objetivo(s) dentro do processo de ensino aprendizagem. O seu caráter recreativo é suprimido, de modo que a atividade é imposta com muitas exigências, regulamentada e cronometrada.

Nesse sentido, todas as respostas que foram incluídas nessa categoria "O jogo é um instrumento do(a) professor(a)", foram respostas que não contemplaram a dimensão lúdica, de alegria, de humor do jogo, do prazer em jogar. E levar em consideração o lúdico, aqui, significa dizer que os jogos não só contribuem para o desenvolvimento intelectual dos alunos, mas que potenciam a criatividade e tantas outras habilidades, por exemplo.

Outro ponto importante é o fato de que muitas das respostas, sinalizavam a ideia de que, por meio dos jogos, os(as) alunos poderiam desenvolver diversas habilidades, dentre elas as socioemocionais, além das cognitivas. Como por exemplo: "[...]socializar com os outros [...]"; "[...] o aluno se sentirá mais seguro no seu aprendizado." e "[...] Trabalhar o senso comum e atividades em grupo.". Isto indica, que o efeito que os jogos podem trazer, enriquecendo interações humanas não são ignorados por esses educadores(as).

Consultamos professores de diversas áreas do conhecimento dentro da Educação Básica, sendo que do total dos respondentes 45,4\% eram pedagogos(as), 16,4\% matemáticos, 10,9\% licenciados(as) em Língua Portuguesa, igual percentual em Ciências, 7,3\% historiadores(as), 5,5\% geógrafos(as) e 3,6\% professores(as) de Educação Física. Este foi um dado positivo, pois evidencia que o jogo auxilia no processo de ensino-aprendizagem nas diversas disciplinas da Educação Básica.

É importante ressaltar neste quesito que o fato da maioria dos(as) professores(as), de diversas áreas de atuação, reconhecerem o uso do jogo como potencializador da aprendizagem, não significa dizer que os docentes planejam e organizam situações para que os jogos ocorram em sua sala de aula.

Página | 17 


\title{
Game use as a learning enhancer: a perspective of teachers of basic education
}

\begin{abstract}
This article is an excerpt of the master's research developed in the Graduate Program in Education in Science and Mathematics of the Federal University of Pernambuco, the work developed aims to present the analysis from the perspective of teachers, primarily in Elementary Education, who work in schools in the municipal public schools of Maceió/AL that are partners of Mind Lab in the application of the Mentelnovadora Program, in order to identify whether they are clear or not on how the use of games as a teaching methodology can enhance the teaching process and learning and favor the development of favorable attitudes for learning its curricular component. Based on a qualitative, descriptive and field methodology, we consulted teachers and professors from different areas of knowledge in basic education and there was an effort on their part to understand the importance of the role of the game in human development cognitive and psychological and emotional balance, both in children, adolescents and young people; although we perceive a tendency to link the act of playing in the classroom with the idea of hobby, distraction. It is mentioned in the answers to the questionnaire applied with the teachers, from the Content Analysis in Bardin (2011), that the game itself does not guarantee learning, and that the game, as well as the play, must be understood as an opportunity to build learning. In this context, we will highlight here the perspective on the use of games in education by authors such as Kishimoto (2003 and 2011), Antunes (1998) and Borin (1998).
\end{abstract}

KEYWORDS: Game. Education. Methodology. Teaching. 


\section{REFERÊNCIAS}

ANTUNES, Celso. Jogos para a estimulação das múltiplas inteligências. Rio de Janeiro: Vozes, 1998.

BARDIN, Laurence. Análise de conteúdo. São Paulo: Edições 70, 2011.

BORIN, Julia. Jogos e resolução de problemas: Uma estratégia para as aulas de matemática. 3a ed., São Paulo; Caem, 1998.

GIL, Antonio Carlos. Como elaborar projetos de pesquisa. 4. Ed. São Paulo: Atlas, 2008.

IDE, Sahda Marta. O jogo e o fracasso escolar. In: KISHIMOTO, Tizuko Morchida (org.). Jogo, brinquedo, brincadeira e a educação. 14. ed. São Paulo: Cortez, 2011. p.99-120.

KISHIMOTO, Tizuko Morchida (org.). Jogo, brinquedo, brincadeira e a educação. 14 ed, São Paulo, Cortez, 2011.

KISHIMOTO, Tizuko Morchida. O jogo e a educação infantil. São Paulo, Pioneira Thomson Learning, 2003.

Projeto Pedagógico Mind Lab. Disponível em:

<http://www.mindlab.com.br/mindlab/ wp-content/uploads/2014/04/ProjetoPedag\%C3\%B3gico-Mind-Lab_Vol1.pdf>. Acesso em: 09 de 2016.

TEIXEIRA, Sirlândia Reis de Oliveira. Jogos, brinquedos, brincadeiras e brinquedoteca: implicações no processo de aprendizagem e desenvolvimento. Rio de janeiro: WAK, 2010.

Recebido: 07 ago. 2019

Aprovado: 26 fev. 2020

DOI: $10.3895 /$ actio.v5n1.10477

Como citar:

MELO, H. B. M. de. Uso do jogo como potencializador da aprendizagem: uma perspectiva de docentes da educação básica. ACTIO, Curitiba, v. 5, n. 1, p. 1-19, jan./abr. 2020. Disponível em:

$<$ https://periodicos.utfpr.edu.br/actio>. Acesso em: XXX

Correspondência:

HELISABETY BARROS MENDES DE MELO

Rua Olindina Campos Texeira, $n^{\circ}$ 52, Edf. Monte Sinai, apto. 606, Cep.: 57036-690, Bairro Jatiúca, Cidade Maceió, Estado Alagoas, Brasil.

Direito autoral: Este artigo está licenciado sob os termos da Licença Creative Commons-Atribuição 4.0 Internacional.

(c) (i) 